\title{
CLOSE RANGE PHOTOGRAMMETRY APPLIED TO THE DOCUMENTATION OF AN ARCHAEOLOGICAL SITE IN GAZA STRIP, PALESTINE.
}

\author{
Emmanuel ALBY ${ }^{\mathrm{a}^{*}}$, René ELTER ${ }^{\mathrm{b}}$, Caroline RIPOCHE ${ }^{\mathrm{a}}$, Nolwenn QUERE ${ }^{\mathrm{a}}$ \\ INSA de Strasbourg \\ ${ }^{a}$ Icube laboratory, Photogrammetry and Geomatics , Graduate School of Science and Technology (INSA), 24 Boulevard de la \\ Victoire, 67084 STRASBOURG, France \\ (emmanuel.alby, caroline.ripoche, nolwenn.quere)(at)insa-strasbourg.fr \\ ${ }^{\mathrm{b}}$ Director of French-Palestinian archaeological mission in Tell Umm el-Amr, Gaza strip \\ Lorraine university, EA 1132 Hiscant-Ma \\ French Biblical and Archaeological School (EBAF), 6 Nablus Road P.O.B. 1905391190 Jerusalem JERUSALEM \\ elter.archeo(at)wanadoo.fr
}

KEY WORDS: Photogrammetry, archaeology, Cultural Heritage

\begin{abstract}
:
In a geopolitical very complex context as the Gaza Strip it has to be dealt with an enhancement of an archaeological site. This site is the monastery of St. Hilarion. To enable a cultural appropriation of a place with several identified phases of occupation must undertake extensive archaeological excavation. Excavate in this geographical area is to implement emergency excavations, so the aim of such a project can be questioned for each mission. Real estate pressure is also a motivating setting the documentation because the large population density does not allow systematic studies of underground before construction projects. This is also during the construction of a road that the site was discovered. Site dimensions are $150 \mathrm{~m}$ by $80 \mathrm{~m}$. It is located on a sand dune, $300 \mathrm{~m}$ from the sea. To implement the survey, four different levels of detail have been defined for terrestrial photogrammetry. The first level elements are similar to objects, capitals, fragment of columns, tiles for example. Modeling of small objects requires the acquisition of very dense point clouds (density: 1 point $/ 1 \mathrm{~mm}$ on average). The object must then be a maximum area of the sensor of the camera, while retaining in the field of view a reference pattern for the scaling of the point cloud generated. The pictures are taken at a short distance from the object, using the images at full resolution. The main obstacle to the modeling of objects is the presence of noise partly due to the studied materials (sand, smooth rock), which do not favor the detection of points of interest quality. Pretreatments of the cloud will be achieved meticulously since the ouster of points on a surface of a small object results in the formation of a hole with a lack of information, useful to resulting mesh. Level 2 focuses on the stratigraphic units such as mosaics. The monastery of St. Hilarion identifies thirteen floors of which has been documented years ago by silver photographs, scanned later. Modeling of pavements is to obtain a three-dimensional model of the mosaic in particular to analyze the subsidence, which it may be subjected. The dense point cloud can go beyond by including the geometric shapes of the pavement. The calculation mesh using high-density point cloud colorization allows cloud sufficient to final rendering. Levels 3 and 4 will allow the survey and representation of loci and sectors. Their modeling can be done by colored mesh or textured by a generic pattern but also by geometric primitives. This method requires the segmentation simple geometrical elements and creates a surface geometry by analysis of the sample points. Statistical tools allow the extraction plans meet the requirements of the operator can monitor quantitatively the quality of the final rendering. Each level has constraints on the accuracy of survey and types of representation especially from the point clouds, which are detailed in the complete article.
\end{abstract}

\section{INTRODUCTION:}

It is sometimes difficult to differentiate the scientific problem with his application. The site of our study is subject to many constraints. The project described in this article concerns the development of the Monastery of St. Hilarion in the Gaza Strip. The discussion on the choice of the device used cannot take place. The camera can only be used, inexpensive and commonplace. The technique that imposes this device is therefore the photogrammetry. Everything must be done with. The site is a huge potential both in terms of archeology and 3D survey. A small number of people can enter the Gaza Strip to work on the site. When he succeeds to get to the monastery, the archaeologist is sometimes the only one to work on the site. We must focus much of our efforts on the transmission of photogrammetric survey methods, as the archaeologist must advance its archaeological discovery of the monastery, but also must be able to document it. The exclusive use of photogrammetry induces significant post-treatment, but they can be made elsewhere and at another time. The few existing resources locally, financial and human, cannot prevent a slow destruction of the site. It may as well be completely destroyed suddenly. Emergency archaeology requires speed and efficiency of the survey on site. In this article we will discuss the benefits that can be derived from photogrammetry, which even if it is used in this context by fate, is an excellent alternative.

\section{PHOTOGRAMMETRY AND ARCHAEOLOGY:}

The construction of knowledge in archeology is based on learning from objects found during excavations. To understand these artifacts the issue of representation is important. The progress of the excavation is subject to economic constraints that impose an accelerated survey of stratigraphic elements to maximize advancement. The systematic design comes to be questioned because it requires considerable time.

\subsection{Acquisition during excavations:}

The remote acquisition techniques, such as 3D scanning and photogrammetry provide an attractive alternative in terms of timeliness. The introduction of these techniques in the codified process of archeology, raises a question about the contemporary 
methodology, and is controversial. The use of these techniques also offers significant opportunities for development. Although the use of these techniques raises further questions, they can be easily integrated into the methods archaeologists. Allowing extending the exploration of stratigraphic stage beyond their destruction, they provide opportunities to increase the potential for an archaeological excavation. Although the complementarity of laser scanner and photogrammetry is demonstrated, a choice between the two techniques must be made to limit the technical aspects of the survey. The choice of photogrammetry has been done for the presented and developed throughout this article. The introduction of an additional technique in an existing method involves an adaptation of the participants for a successful integration. Use of photogrammetry for the archaeologist who already owns and uses a camera is just a learning of acquisition methods.

Photographic documentation is already used by the archaeologist, he just have to ensure the successful 3D documentation. Regarding the acquisition, only the additional time linked to the achievement of photogrammetric data sets must be taken into account as a change in the survey method. No hardware investment is expected. In a very difficult economic environment, photogrammetry is a considerable asset. The time spent in the field should be limited to the maximum, so that once the stage of excavation is completed, it is necessary to organize the information collected and the photogrammetric processing. It is interesting to make the archaeologist acquires himself photogrammetric data for rapid documentation and complete as possible, it is not essential that he operate alone during photogrammetric processing. The post-excavation period is less constrained by time, tasks can be distributed.

Treatments to get 3D data from the pictures of the object, are made later by computer regardless of time and place of purchase. The acquisition of 3D objects extracted from the excavation is also done in a second time, whenever the constraint binds lower.

\subsection{Photogrammetry, an affordable technique}

These are the latest innovations and implementations of algorithms that allow greater automation of these treatments. The use of photogrammetry also allows the most complete documentation possible to all objects that have been identified. This allows an effective preservation of cultural heritage. Unlike other $3 \mathrm{D}$ acquisition techniques, photogrammetry allows a multiscale approach with a single device; it is possible to identify objects of different dimensions, such as a capital, a ruined building, and an archaeological excavation.

The principles of photogrammetry existed even before the invention of photography. For over a century, applications in archeology have been highlighted. However, the technical skills needed to obtain representations have always been a major obstacle to its democratization. The interest of archeologists in this technique, the source of information that is now faster and more automatic increases significantly with free access to effective solutions. This progress is due to a rapprochement between the computer vision techniques and principles necessary to obtain reliable data in photogrammetry.

Detectors points of interest in the images have been enhanced to allow their recent implementation of effective way for the relative orientation of images (Juan, 2009). These points of interest are now recognized with a robustness that allows consideration of objects of varying sizes between different images (Dufournaud, $2000 \&$ Ke, 2004). By comparing these tools we can find a compromise to their best use. Solutions with automatic orientation have been derived such as Bundler (Snavely, 2007) and Apero (Pierrot-Deseilligny, 2011). For this project, we use Bundler based solutions: Visual SFM (Wu,2010).

Automation continues with the production step of point clouds or densification. At the end of this step the data generated are comparable to those produced by a laser scanner (Alby, 2009). Automatisation of the relative orientation and densification are the critical stages for use by non-specialists photogrammetry and the democratization of the growing application to the representation in archeology.
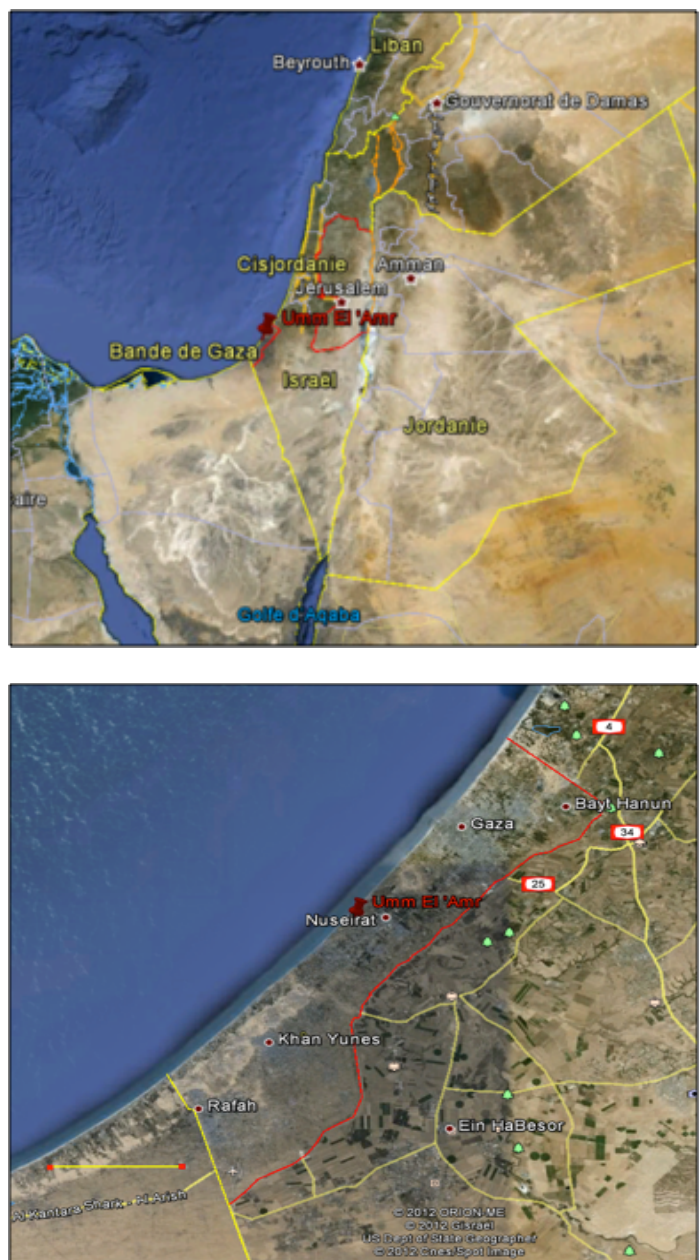

Figure 1: Location of the site (google maps)

The point cloud as a dimensional analogy between virtual and real, is a witness of the state of the observed object. It is neither a model nor a representation. The point cloud must go through one or more transformations. The mesh is the most commonly used (Grussenmeyer, 2010 \& 2011), but modeling primitives allows significant simplification while maintaining fidelity to the characteristics of the object (Alby, 2011 \& 2012). Traditional two-dimensional representations must not be forgotten (Landes, 2007). With regard to the survey of the St. Hilarion monastery archaeological site, small equipment required is very advantageous. The camera is already in use on the site, so no additional hardware is required. The shooting method, which is suitable for this technique is available to archaeologists and allows complete independence on the field, 
giving the possibility to intervene at different times. The reduced time on site makes use of photogrammetry relevant, by the time saved for the periodic statement. The situation in which the project is part of photogrammetric documentation, allows the digital preservation of the site, even if the primary purpose of shooting is the $3 \mathrm{D}$ modeling.

\section{PHOTOGRAMMETRIC SURVEY OF ST. HILARION SITE}

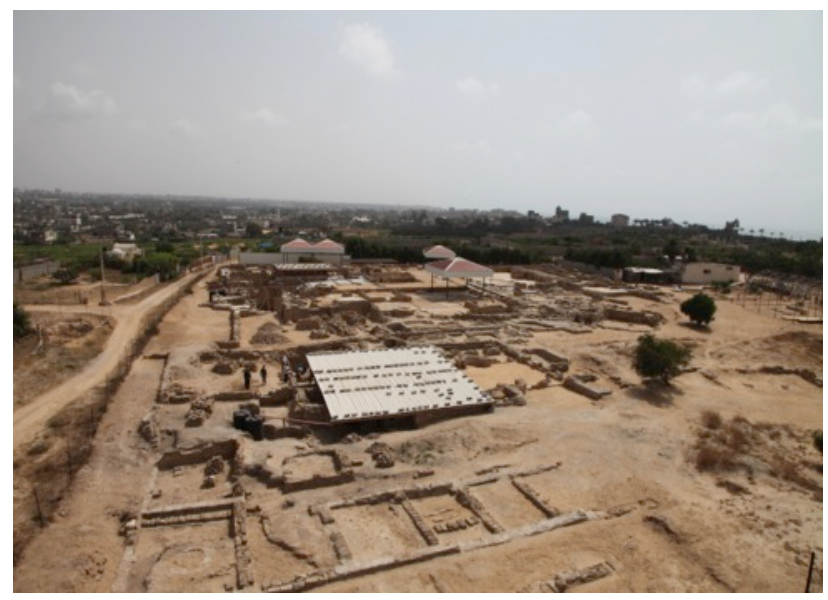

Figure 2: Partial view of achaeological site

The objective of this chapter is to present the monastery of St. Hilarion. This chapter describes the means used to carry out this mission.

The Monastery of Saint Hilarion was discovered in Gaza. The remains of the monastery are located in the municipality of Nuseirat, $10 \mathrm{~km}$ south of Gaza City. The remains extend over 1.5 hectares and are located on a dune overlooking a palm grove and the sea, about $300 \mathrm{~m}$. A Byzantine architectural complex was discovered in 1997 by the Department of Antiquities in Gaza during construction. The remains are those of a Byzantine monastery and a bathhouse, dating from the Umayyad period. In 2003, an inscription refers to the place as dedicated to the cult of St. Hilarion father of monasticism in the Middle East who lived in the fourth century, and whose texts mention the location of the foundation Tell Umm El'Amr. Since 2001, the mission of French-Palestinian archaeological cooperation in Gaza, led by EBAF leads the complete study remains with the purpose of restoration and tourism development.

The full documentation of such a site is the result of a compromise between the need dictated by the respective dimensions of the elements to identify and scales commonly used representation. Six levels of detail involving a suitable and relevant representation acquisition mode have been developed.

The first level includes elements similar to objects, capitals, columns or tile fragment, for example. Modeling of small objects requires the acquisition of very dense point clouds (density: 1 point $/ 1 \mathrm{~mm}$ on average). The pictures are taken at a short distance from the object, the images are used to their full resolution. The main obstacle to the modeling of objects is the presence of noises in part due to the studied materials (sand, smooth rock) that do not support the detection of points of interest in quality.
The second level focuses on the stratigraphic units. It concerns for example the modeling of mosaic pavements and modeling of an area of excavations at various stages of completion. The purpose of this document is to observe the evolution of excavation over time but also to identify a site stratigraphy. Acquisitions succeeding in the same place but with changing configurations, you must be sure to overlap the data obtained by ensuring have common parts. Representations of the Level 2 are either a textured 3D mesh if the object is complex, an orthophoto if the object is similar to a plan or a plan drawn from the ortho-photo for specific items.

Levels 3 and 4 will allow the survey and representation of loci and sectors. Their modeling can be done by mesh textured but also by geometric primitives. This method requires segmentation into simple geometric elements and creates a geometric surface by analyzing the sample points. Statistical tools allow the extraction plans comply with the requirements of the operator can control quantitatively the quality of the final rendering.

3D modeling of levels 5 and 6 , respectively $3 \mathrm{D}$ ground plane and $3 \mathrm{D}$ map location is not possible with the use of terrestrial photographs only. The ideal would be to cover the area with shots taken from an aerial point of view. Generating a digital surface model allows the creation of ortho-photos and 3D ground plan.

The establishment of these levels of detail is a compromise between the size of the objects of interest and the need for precision representation. The levels are defined in relation to prescribing mode of shooting images. Indeed, depending on the level of detail in which we work, acquisition methods will be different. For levels 1 and 2, the shooting will converge around the object while for levels 3 and 4 , it will make possible the acquisition of space and connect the walls that surround them. Point clouds will be produced after pictures process.

\section{RESULTS}

The project is in progress; the results are derived from exploratory studies on different levels of detail identified. Indeed, it is conceivable to identify and produce data from isolated or single locus objects without difficulty, it becomes more complex to manage the production of an entire sector.

\section{Level 1 and 2}

The elements considered in level 1, these items are easy to go around, even if they can be difficult to handle as the capital presented in Figure 3. As mentioned in 2.2 point cloud is not a goal, it is nevertheless possible to make treatment for easier visualization. A process of the gray level of the points according to their relative position reveal the flat area caused by the true colors.

Many mosaics found on the site of the monastery were documented prior to the use of photogrammetry on site. The pictures had been taken in order to be rectified. Their overlap is quite large; tests were performed on data sets. The results are quite conclusive as shown in Figure 4. All mosaics are not necessarily still on the site. Indeed, some of them were taken out to keep them elsewhere on the site that is deteriorate over time. Photogrammetry allows here to produce $3 \mathrm{D}$ data with images of objects that are no longer in place or have disappeared. 
Level 3:

Level 3 is used to describe the space or locci. The ruins of the site of the Monastery of Saint Hilarion for understanding the spaces were and their relationships. A very large part of the site has been documented to enable $3 \mathrm{D}$ reconstruction of these areas. Figure 5 depicts the excavation currently in progress. Each stratigraphic layer was photographed to allow reconstructing a complete history of the excavation.
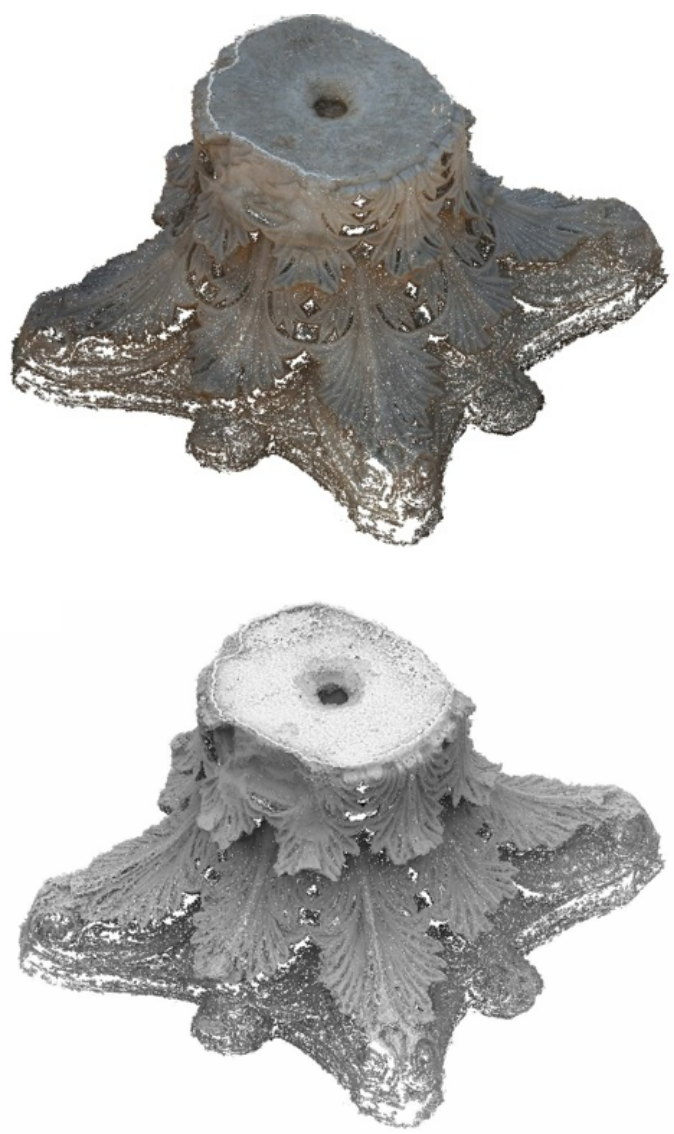

Figure 3: point cloud of a capital from St. Hilarion Monastry by photogrammetry, without color on the bottom, colored on the top

Level 4:

It is with the level of detail 4, which can understand the sectors that include spaces with their use. These sectors represent areas of several thousand square meters. Sectors of the site of the monastery of St. Hilarion do not have the same dimensions. For example the crypt can be considered as a major locus. It was possible to process it in one big project (around 1000 frames). This limit cannot easily be exceeded. Figure 6 shows the crypt modeled.

The topographic data acquired on the site does not allow an absolute referencing. A sector cannot yet be reconstructed by grouping geo-referenced locci. The current solution is to try to produce point clouds with a maximum of images and fit them with the clouds overlap. One sector has been taken as a test to validate this approach. This sector lies to the west and consists of monk cells, the atrium of the monastery refectory and technical rooms. Figure 7 shows the textured mesh of this sector.

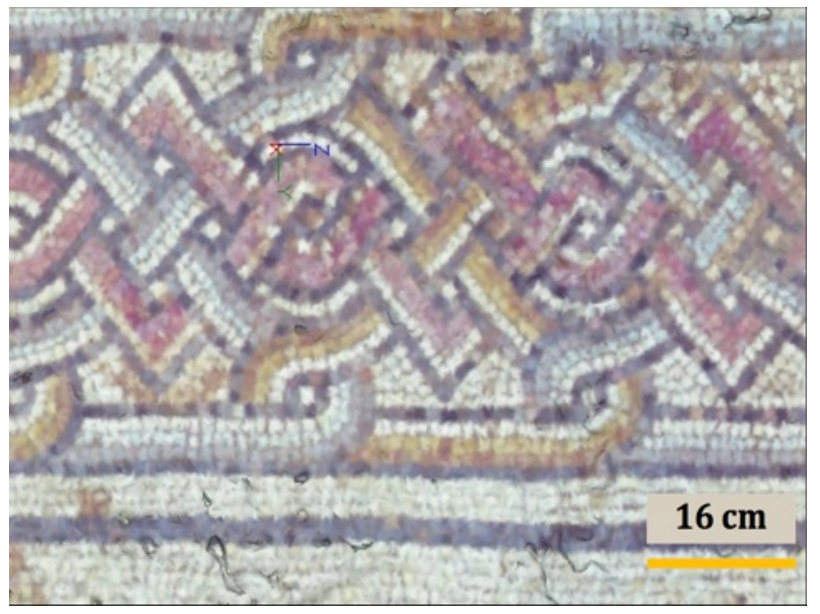

Figure 4: extract of 3D model of mosaic \#3. Squared tessera can be remarked.
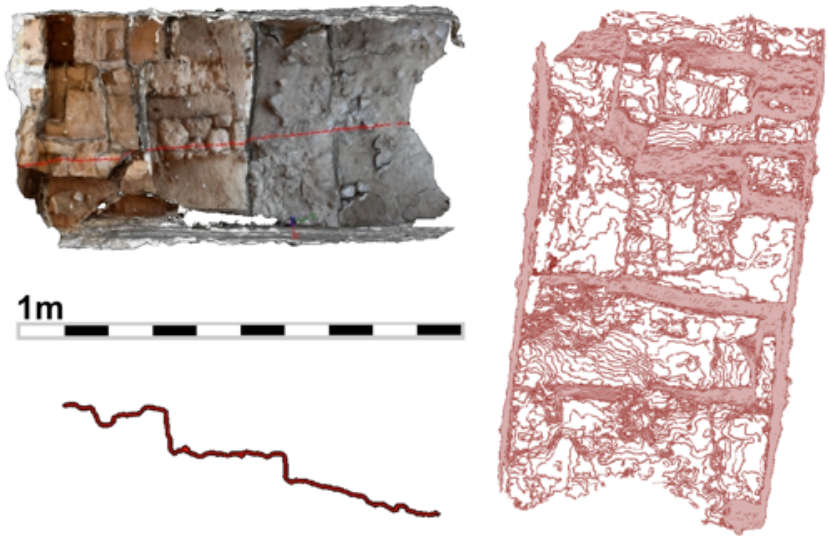

Figure 5: intermediate state of the excavation and representation extracted from photogrammetric data. Top left: Textured mesh, bottom left section following red axe on mesh, right contour line

\section{CONCLUSION}

The context of the work of development of monuments in Gaza, gives a photogrammetry tool essential scientific status. Its practicality and speed survey allow archaeologists to document an excavation site effectively. The adaptability of the method to all sites provides comprehensive modeling of the site with technical means reduced to a camera, a computer and a survey rod. Batch processing of data sets allows the archaeologist to make his survey independently in parallel of excavation and thus save valuable time in the field whose accessibility is constantly threatened. The methods developed in this project raises many issues that will be studied in the short and long term, particularly in terms of controlling the point clouds noise, the consolidation of models and their ranking in the space. The automation of certain aspects of the processing chain is to consider seriously in view of the spatial and temporal extent of the archaeological site. 


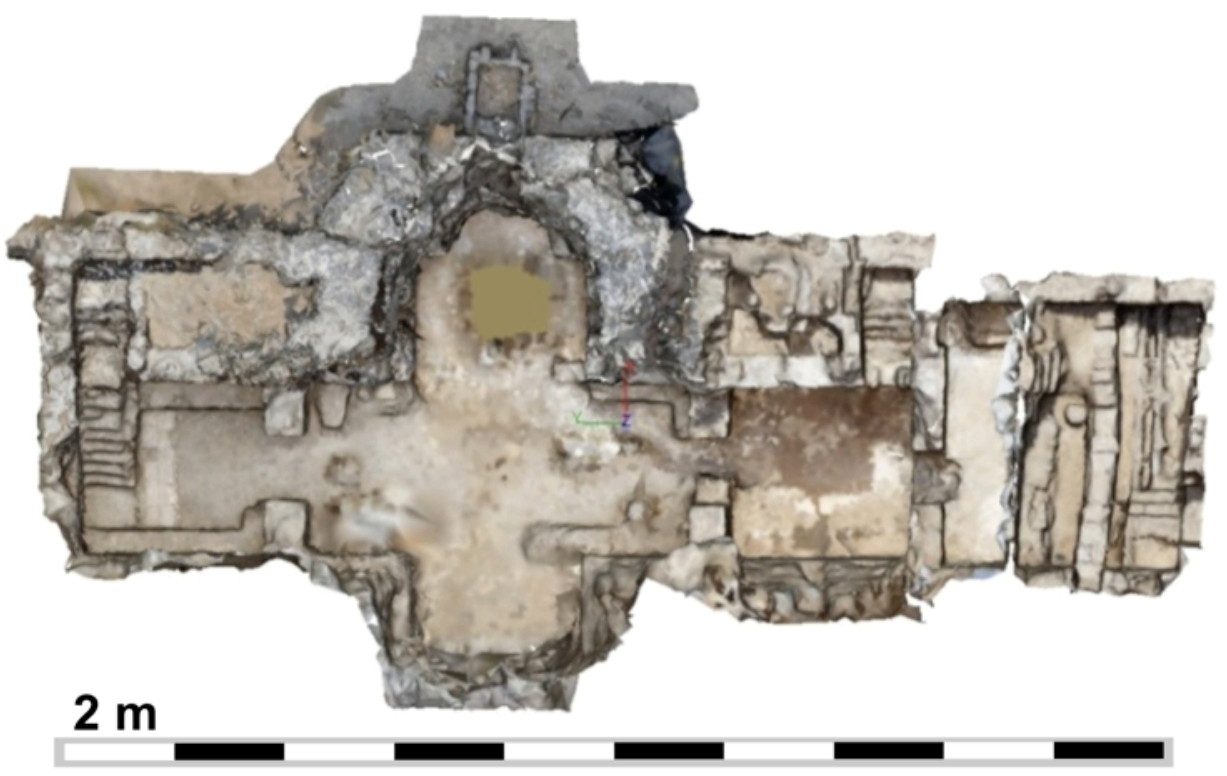

Figure 6: Point cloud of the crypt, top view.

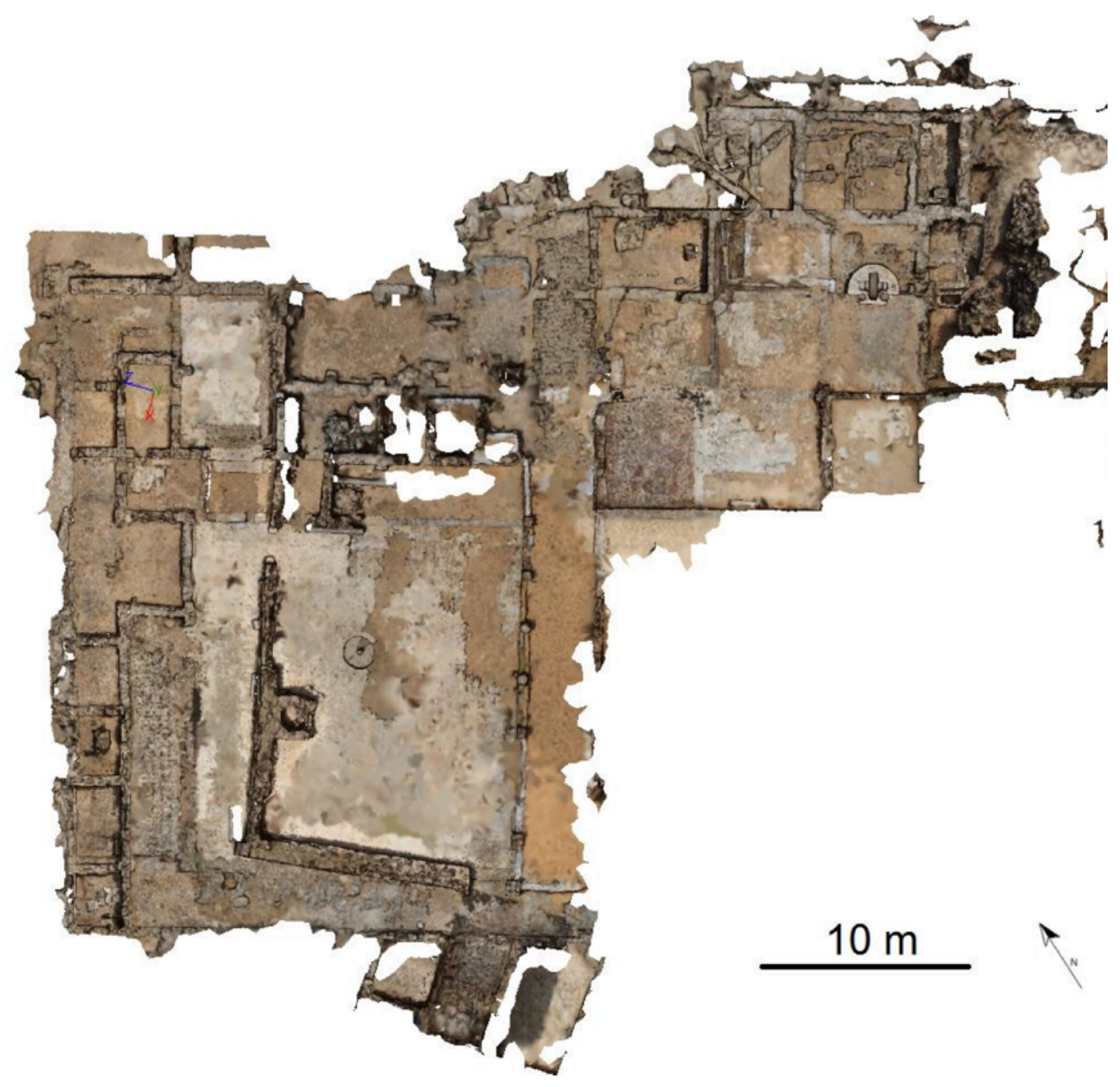

Figure 7: textured mesh of sector 2, top view. 


\section{BIBLIOGRAPHY:}

E. Alby, P. Grussenmeyer - From point cloud to 3D model, modelling methods based on architectural knowledge applied to fortress of châtel-sur-moselle (France). XXIIth ISPRS Congress, Melbourne, Australia, Int. Archives of Photogrammetry, Remote Sensing and Spatial Information Sciences August 2012.

E. Alby, P. Grussenmeyer, V. Poitevin - From 3D recording to virtual visit of archaeological sites : methodology applied to the medieval fortress of châtel-sur-moselle (France). In: XXIIIrd International CIPA Symposium. Prague, Czech Republic. CIPA International Archives for Documentation of Cultural Heritage, 2011.

E Alby, E Smigiel, P Assali, P Grussenmeyer, I KauffmannSmigiel - Low cost solutions for dense point clouds of small objects: PhotoModeler Scanner vs. David Laserscanner. In: XXIInd International CIPA Symposium. Kyoto, Czech Japan. CIPA International Archives for Documentation of Cultural Heritage, 2009.

Y. Dufournaud, C. Schmid, and R. Horaud. Matching images with different resolutions. In Proceedings of the Conference on Computer Vision and Pattern Recognition, Hilton Head Island, South Carolina, USA, June 2000.

P Grussenmeyer, E Alby, P Assali, V Poitevin, JF Hullo, E Smigiel - Accurate documentation in cultural heritage by merging TLS and high-resolution photogrammetric data SPIE Optical Metrology, 808508-808508-13. 2011

P Grussenmeyer, T Landes, E Alby, L Carozza - High Resolution 3D Recording and Modelling of the Bronze Age Cave "les Fraux" in Périgord (France). ISPRS Comm. V Symposium, Newcastle upon Tyne, June 2010.

L. Juan, O. Gwon - A comparison of SIFT, PCA SIFT and SURF. International Journal of Image processing, vol. 4. 2009

Y. Ke, R. Sukthankar - PCA-SIFT : A more distinctive representation for local image descriptors, 2004.

T. Landes , P. Grussenmeyer, T. Voegtle, K. Ringle

Combination of terrestrial recording techniques for $3 \mathrm{D}$ object modeling regarding topographic constraints. Example of the castle of Haut-Andlau, Alsace, France. in XXIth International CIPA Symposium, Athens, Greece CIPA International Archives for Documentation of Cultural Heritage, 2007

M. Pierrot-Deseilligny, I. Cléry. APERO, an Open Source Bundle Adjusment Software for Automatic Calibration and Orientation of a Set of Images. Proceedings of the ISPRS Commission V Symposium, Image Engineering and Vision Metrology, Trento, Italy, 2-4 March 2011.

N. Snavely, S. M. Seitz, R. Szeliski. Modeling the World from Internet Photo Collections. International Journal of Computer Vision, 2007.

C. Wu - VisualSFM : A Visual Structure from Motion System, Changchang $\mathrm{Wu}$, University of Washington at Seattle.

$\mathrm{http} / / /$ homes.cs.washington.edu/ ccwu/vsfm/. 2010 